Contact Capacity and its Effect on Intergroup Relations

Miriam Pfister, Ralf Wölfer and Miles Hewstone

University of Oxford, Department of Experimental Psychology

Author Note

The CILS4EU research project was funded by the NORFACE ERA NET Plus Migration in Europe-programme.

Miriam Pfister and Ralf Wölfer, Department of Experimental Psychology, University of Oxford, United Kingdom; Miles Hewstone, Department of Experimental Psychology, University of Oxford, United Kingdom and University of Newcastle, Australia.

Correspondence concerning this article should be addressed to Miriam Pfister, Department of Experimental Psychology, University of Oxford, Anna Watts Building, Radcliffe Observatory Quarter, Woodstock Road, Oxford OX2 6GG, United Kingdom. Email: $\underline{\text { miriam.pfister@psy.ox.ac.uk }}$ 


\begin{abstract}
Although intergroup contact is an effective means to improve intergroup attitudes (Allport, 1954; Pettigrew \& Tropp, 2006), it does not always have a positive impact on them. This study introduces contact capacity as a factor that may impede intergroup contact. Longitudinal social network data $\left(N=6,600 ; M_{\text {Age }}=14.87\right.$ years $)$ was collected in Germany, the Netherlands and Sweden and used to accurately calculate participants’ outgroup, ingroup, and total contact. Multilevel models (L1: students, L2: school classes) showed that the total amount of contact at wave 1 negatively predicts individuals’ outgroup friends at wave 2 while controlling for outgroup attitudes, existing outgroup friendships and sociodemographic variables. An additional robustness check showed that this effect holds true for future ingroup friendships. The study highlights the importance of contact capacity for whether people engage in intergroup contact, and the contribution of social network analysis to contact research.

Keywords: contact capacity, intergroup contact, cross-group friendships, social network analysis
\end{abstract}




\section{Contact Capacity and its Effect on Intergroup Relations}

Growing up in multi-ethnic, multicultural societies provides an opportunity for prejudicereducing outgroup contact but also holds the risk of discrimination or social exclusion, often targeting immigrants or ethnic minorities (van der Meer \& Tolsma, 2014). Allport’s (1954) ‘contact hypothesis’ assumes that direct, face-to-face contact between members of different groups can reduce prejudice, an effect that is augmented under optimal conditions (e.g., equal status, opportunity to have meaningful interactions and disconfirm stereotypes, a context requiring cooperation, and norms from authority figures that support such interactions). In their meta-analysis, Pettigrew and Tropp (2006) aggregated results from 515 cross-sectional studies, using direct contact as an independent and prejudice as the dependent variable, which revealed a positive effect of intergroup contact on prejudice $(r=-.215, p<.001)$. Given that intergroup prejudice can threaten cohesion in multicultural societies, it is thus important to facilitate beneficial intergroup contact. However, aspects such as the lack of contact opportunities (Turner, Hewstone, \& Voci, 2007), segregation (Laurence, Schmid, Rae, \& Hewstone, in press) or homophily (McPherson, Smith-Lovin, \& Cook, 2001; Wölfer \& Hewstone, 2018) can impede intergroup contact.

Another, thus far neglected, factor that can limit the formation of outgroup contact is what we refer to as contact capacity. We define contact capacity as the maximum extent to which an individual is cognitively and socially able to adequately manage and maintain relationships with other people. We believe that it is important to consider contact capacity, because research indicates that individuals do not always take up existing contact opportunities (Wölfer \& Hewstone, 2018). A possible explanation for this rather inconsistent take-up of contact opportunities might be that some people's social network is too saturated (i.e., it has 
reached the full capacity of possible interpersonal contacts) to enable them to engage in new contacts, irrespective of their outgroup (and ingroup) attitudes. As a result, additional intergroup contact may exceed the cognitive and social capacity needed to invest in new social relationships (e.g., Saramäki et al., 2014) and thus fail to result in more positive intergroup attitudes.

\section{Contact Capacity as a Cognitive and Social Constraint}

The idea of contact capacity is based on three independent lines of research. First, contact capacity is based on the need to belong as a fundamental motivation that drives people naturally towards forming and maintaining lasting, positive and significant interpersonal contacts, at least until they have reached a satisfying level of social relatedness (Baumeister \& Leary, 1995). Thus, people who already have a sufficient number of social bonds that satisfy their need to belong should form fewer additional relationships in comparison to people lacking or still in need of sufficient bonds. In line with this view, social contact is specified as a basic human motivation which is related curvilinearly with well-being, comparable to the need to sleep or eat: After a certain threshold is reached, people should avoid further saturation (Baumeister \& Leary, 1995). In an experimental context, socially excluded, compared to integrated, individuals have a selective attention and memory for social events (Wölfer \& Scheithauer, 2013). As social exclusion threatens belongingness, these individuals devote more attention to actions that promise to fulfill their need to belong (e.g., making a new acquaintance).

Second, the nature of cross-group friendships provides further support for the idea of contact capacity. In more detail, cross-group friendship as a key form of intergroup contact represents a powerful strategy for overcoming group-based prejudice (Davies, Tropp, Aron, Pettigrew, \& Wright, 2011; Pettigrew \& Tropp, 2006). Mutual trust has been shown to play a key role when becoming friends with outgroup members (Shelton, Trail, West, \& Bergsieker, 2010). 
However, trust builds gradually over the course of developing relationships and requires time and effort. In other words, forming cross-group friendships is cognitively and socially demanding as it involves costs, such as the time spent together, which has been shown to be one of the indicators that best captures the degree of one's actual engagement in the relationship (Davies et al., 2011).

Third, 'Dunbar's number' assumes a layered network structure that limits our contact capacity up to, on average, about 150 individuals with whom we (can) have a meaningful personal relationship (Zhou, Sornette, Hill, \& Dunbar, 2005). Both cognitive and temporal restrictions prevent individuals from having a steadily increasing number of meaningful relationships (Dunbar, 1993): aside from an inability to keep track mentally of more than 150 people, the amount of time individuals can distribute across network members in their everyday life is limited. As a result, most individuals are unable to allocate sufficient time to develop or maintain real relationships with all members of their social network. Twenty-five years of research on ego networks has investigated individuals’ limited cognitive capability to successfully manage an ever-increasing number of social contacts (e.g., Saramäki et al., 2014) and revealed support for the idea that a person's contact capacity - whether it is a total number of 150 people or not - is limited.

Applying this work to the present context of intergroup contact, we expect individuals with many friends to form fewer new outgroup contacts compared to individuals with only a few friends. Based on this theoretical reasoning, the effect should hold for ingroup contact as well. Despite the theoretical relevance of contact capacity, its potential influence has been, to our knowledge, largely ignored in intergroup contact research. One explanation for this could be based on the traditional method that contact researchers use. Studies typically rely on self-reports 
(81\% of the studies in Pettigrew and Tropp’s, 2006, meta-analysis did so), which might be interpreted quite differently by different participants and give only a rough idea about a person's precise level of overall contact. Thus, this method makes it is difficult to empirically consider individuals contact capacity. In contrast, social network analysis (SNA) enables us to overcome this limitation as it allows us to measure precisely contact capacity (for a brief introduction, see Wölfer \& Hewstone, 2017; for further introduction to SNA, see Clifton \& Webster, 2017) - in the case of intergroup contact, when considering the degree of a person's integration into the social network by counting the exact number of reciprocal inter- and intragroup 'ties’ (or links). Only a few studies have, thus far, applied the advantages of SNA and validated its use to adequately examine developmental and contextual facets of intergroup contact dynamics (e.g., Munniksma, Stark, Verkuyten, Flache, \& Veenstra, 2013; Wölfer, Schmid, Hewstone, \& van Zalk, 2016).

\section{Research Objectives}

The present study aims to improve our understanding of intergroup contact as we examine the influence of contact capacity on intergroup relations. The use of SNA allows us to measure relationships among the network members and provide valuable insights into peoples’ contact capacity, their level of social saturation and its influence on future inter- and intragroup relations. We consider both contact quantity and quality: SNA allows us to precisely consider the quantity of contact as we count the number of outgroup (and ingroup) ties within the social network of each participant by relying on self-reported friendship ties. As the measure of reciprocal friendship networks assesses an optimal measure of the quality of the relationship (a true friendship between A and B should clearly involve a reciprocal, and not merely one unilateral, tie), we can also tap into the concept of contact quality. For this purpose, we use 
longitudinal data that was collected with a one-year gap to capture changes in social networks; this is important because intergroup contact requires time to have an effect (Pettigrew, 1998). Moreover, we explicitly take both majority and minority perspectives into account in order to gain a better understanding of intergroup contact effects among groups of differing status.

We hypothesize that the total amount of contact individuals already have defines, and constrains, the extent to which they are inclined to make contact with new out- and / or ingroup members. Based on the arguments outlined above, we assume that a saturated social network of people decreases one's interest in making contact with out- and / or ingroup members and vice versa due to individuals’ limited contact capacity. We test this hypothesized effect while controlling for intergroup attitudes in order to rule out unfavorable views of the outgroup as an alternative explanation for not forming outgroup contact over time. Specifically, we propose the following hypotheses:

Hypothesis 1: The total amount of contact a person has at wave 1 is negatively related to their future outgroup contact at wave 2 .

Hypothesis 2: The total amount of contact a person has at wave 1 is negatively related to their future ingroup contact at wave 2.

\section{Method}

\section{Sample}

The present study uses network data from waves 1 and 2 of the Children of Immigrants Longitudinal Survey in Four European Countries (CILS4EU, Kalter et al., 2016a, 2016b). The ongoing international collaboration between England, Germany, the Netherlands and Sweden aims to provide information on the processes that drive adolescent immigrants' integration into Western European host countries. Data were collected from stratified school samples at wave 1 
(2010 to 2011) and wave 2 (2011 to 2012) with a one-year time lag. Data for complete social networks was collected, with the school class being the network boundary. The names of the students in each class were collected in advance and allocated a unique identifying number (ID). While attending school, participants filled in the standardized questionnaire as instructed by trained test instructors. A restricted peer nomination procedure was used to gather social network data and identify up to five closest classmates to capture the number of reciprocal friendships of each participant with ingroup and outgroup members.

In the present analysis, we examined data from Germany, the Netherlands and Sweden that provided reliable network data. Due to inconsistencies in how network boundaries were defined, we decided to exclude England from the core analysis in this paper. The target population consists of 14-year old children of native and immigrant origin who were recruited using a stratified sampling design, with four different strata, according to the percentage of children of immigrant orgin in the school: stratum 1: 0-9\%, stratum 2: 10-29\%, stratum 3: 3059\%, stratum 4: 60-100\%. The sample with valid longitudinal data for all relevant study variables at both waves comprised a total of $N=6,600$ students ( $M_{\text {Age }}=14.87$ years; $52 \%$ girls; $\left.n_{\text {Minority }}=2,210\right)$ nested in 353 ethnically mixed school classes and three countries $\left(n_{\text {Germany }}=\right.$ $\left.1,919, n_{\text {the Netherlands }}=2,034, n_{\text {Sweden }}=2,647\right)$.

\section{Measures}

At both waves, a questionnaire was used to gather information about migration-specific characteristics, attitudes towards ethnic outgroup and ingroup members, and social network data. The analysed measures of the present study will be described below. ${ }^{1}$

Direct Contact. We measured direct contact with outgroup (and ingroup) members by using social network data. Participants reported up to five friends within their school class in 
response to the stem, “Who are your best friends in class?”. These network data allowed us to calculate reciprocal relationships. Students were considered to have reciprocal friendships if both students nominated one another among their five best friends within the class, irrespective of whether these friends were in- or outgroup members. Two different types of reciprocal friendships were then identified: first, outgroup friendships (i.e., friendships between majority and immigrant minority adolescents); and second, ingroup friendships (i.e., friendships of both adolescent majority members with other majority group members, and immigrant adolescents with other minority group members). Each student's immigrant background was categorized according to the student's and their parents' birth country or countries, following the secondgeneration definition (i.e., the student or one of their parents was born outside the host country).

Total amount of Contact (Contact Capacity). Using the same peer nomination data, we calculated reciprocal friends at wave 1 and wave 2 by counting all bi-directional links in the network (student A nominated student B and vice versa). Thus, this measure of total amount of contact includes both ingroup and outgroup friends.

Control Variables. We controlled for sex, age, intergroup attitudes and existing outgroup (and ingroup) friends at wave 1 on the individual level, and diversity and class size on the contextual level. Intergroup attitudes, existing reciprocal intergroup friendships, diversity and class size need to be taken into account in the present study as their scores may affect the opportunity for intergroup contact within the school classes. In the given context, intergroup attitudes represent how positively or negatively people think about the respective outgroup (and ingroup). Participants were asked to rate their feelings towards the largest ethnic groups in each respective country using a feeling thermometer on a scale ranging from $0^{\circ}$ to $100^{\circ}$, with higher scores representing more favourable attitudes. Diversity was measured as the percentage of 
minority members in the class and categorized into the four different strata explained above.

Statistical Analysis. Multilevel modeling (Raudenbush \& Bryk, 2002) was used to consider the nested data structure. First, a two-level random-intercept overall model with students on level 1 and school classes on level 2 predicted students' future outgroup contact (Model A) and ingroup contact (Model B) based on the total number of friendships, while controlling for group status (majority versus minority membership), the interaction of group status and total number of friendships, outgroup (and ingroup) contact at wave 1, sex, age and (host) country. Additionally, we controlled for the contextual variables class size and class diversity. Second, we checked for robustness by replicating the overall model with group and country-specific models for majority and minority regarding future outgroup (and ingroup) contact using the same model specification. All continuous variables were z-standardized (i.e., grand-mean centered) to facilitate the interpretation of the regression coefficients. Considering the usual contact effect size of $r=-.215$ (Pettigrew \& Tropp, 2006) and Cohen’s (1988) benchmark for power of .80, power calculations using the r package 'pwr' (Champely et al., 2017) indicated that both main models and each submodel included the necessary number of $N=$ 167 participants in order to detect the hypothesized effects.

\section{Results}

SNA was based on a total of 16,916 reciprocal friendship nominations at wave 1 (per student ${ }_{\mathrm{t} 1}: M=2.5630, S D=1.3878$ ) and 13,131 reciprocal friendships at wave 2 (per student $\mathrm{t}_{2}$ : $M=1.9895, S D=1.3420)$.

Table 1 shows the means of individual study variables separately for majority and minority students. The average correlation of the independent variable and the controls was $r=$ .147, with no individual correlation between independent variable and controls higher than a 
Table 1. Overall Majority- and Minority-specific Means and Standard Deviations.

\begin{tabular}{lccccc}
\hline & \multicolumn{2}{c}{ Majority } & & \multicolumn{2}{c}{ Minority } \\
\cline { 1 - 2 } \cline { 5 - 6 } Variables & Mean & $S D$ & & Mean & SD \\
\hline Total Amount of Contact & 2.6196 & 1.3668 & & 2.4507 & 1.4224 \\
Opportunities for Contact & 2.2339 & 0.9133 & & 2.9271 & 0.9542 \\
with Minorities & & & & \\
Outgroup Contact t1 & .5401 & .7887 & & 1.0457 & 1.2418 \\
Ingroup Contact t1 & 2.0795 & 1.3240 & & 1.4050 & 1.3417 \\
Outgroup Attitudes & 57.6376 & 22.7347 & & 76.5452 & 24.0119 \\
Ingroup Attitudes & 86.4410 & 18.2214 & & 59.9912 & 24.0011
\end{tabular}

Note. Level 1: $n_{\text {Majority }}=4,390$ students, $n_{\text {Minority }}=2,210$ students; Level 2: 353 school classes.

maximum of $r=.740$, which indicates that the different variables considered measured specific aspects of intergroup relations (see supplementary online material).

Multilevel models estimated the overall as well as country-specific differences to assess the influence of contact capacity at time 1 on outgroup (and ingroup) contact at time 2, while controlling for outgroup (or ingroup) contact at time 1 . That is, we tested two models ( $\mathrm{A}=$ future outgroup contact, and B = future ingroup contact). In a first model, we examined the hypothesized effects among majority and minority groups, while testing the interaction between group status and total amount of contact at wave 1 . We then separately tested group-specific differences for the majority and the minority in Models A and B. Thereafter, we replicated the group-specific models in six submodels (three countries, separately for the majority and minority), which allowed us to check the robustness of effects (see our supplementary online material). Tables 2 and 3 summarize Models A and B; Tables 4, 5, 6 and 7 summarize the groupspecific multilevel models that estimated adolescents’ future outgroup and ingroup contact, respectively. 


\section{Overall Future Outgroup and Future Ingroup Contact}

Table 2. Model A: Multilevel Prediction of Future Outgroup Contact.

\begin{tabular}{|c|c|c|c|c|c|c|}
\hline & \multicolumn{6}{|c|}{ Future Outgroup Contact } \\
\hline & $B$ & $S E$ & $95 \% \mathrm{CI}$ & $t$ & $p$ & $D f$ \\
\hline \multicolumn{7}{|l|}{ Level 1: Students } \\
\hline Total Amount of Contact t1 & -.0585 & .0107 & {$[-.0795,-.0375]$} & -5.443 & $<.001$ & 5251 \\
\hline Group Status & .2804 & .0516 & {$[.1793, .3815]$} & 5.432 & $<.001$ & 5251 \\
\hline TotAmCon x Group Status & -.0538 & .0260 & {$[-.1048, .0028]$} & -2.070 & .020 & 5251 \\
\hline Outgroup Contact t1 & .6337 & .0193 & {$[.5959, .6715]$} & 32.797 & $<.001$ & 5251 \\
\hline Outgroup Attitudes & .1981 & .0115 & {$[.1756, .2206]$} & 1.727 & .084 & 5251 \\
\hline Sex & .0026 & .0257 & {$[-.0481, .0530]$} & .102 & .919 & 5251 \\
\hline Age & -.0040 & .0016 & {$[-.0071,-.0009]$} & -2.501 & .012 & 5251 \\
\hline Country (Germany) & .1464 & .0421 & {$[.0639, .2289]$} & 3.476 & $<.001$ & 5251 \\
\hline Country (the Netherlands) & -.0199 & .0399 & {$[-.0981, .0583]$} & -.498 & .618 & 5251 \\
\hline \multicolumn{7}{|l|}{ Level 2: School Classes } \\
\hline Class Size & .0062 & .0151 & {$[-.0234, .0358]$} & .409 & .683 & 350 \\
\hline Diversity & -.0437 & .0181 & {$[-.0792,-.0082]$} & -2.407 & .017 & 350 \\
\hline
\end{tabular}

Note. Level 1: $N=6,600$ students; Level 2: 353 school classes. TotAmCon denotes Total Amount of Contact t1. 
Table 3. Model B: Multilevel Prediction of Future Ingroup Contact.

\begin{tabular}{|c|c|c|c|c|c|c|}
\hline & \multicolumn{6}{|c|}{ Future Ingroup Contact } \\
\hline & $B$ & $S E$ & $95 \% \mathrm{CI}$ & $t$ & $p$ & $D f$ \\
\hline \multicolumn{7}{|l|}{ Level 1: Students } \\
\hline Total Amount of Contact t1 & -.1648 & .0215 & {$[-.2069,-.1227]$} & -7.648 & $<.001$ & 5566 \\
\hline Group Status & -.2177 & .0494 & {$[-.3145,-.1209]$} & -4.410 & $<.001$ & 5566 \\
\hline TotAmCon x Group Status & .0456 & .0261 & {$[-.0056, .0968]$} & 1.751 & .040 & 5566 \\
\hline Ingroup Contact t1 & .6178 & .0222 & {$[.5743, .6613]$} & 27.825 & $<.001$ & 5566 \\
\hline Ingroup Attitudes & .0280 & .0120 & {$[.0045, .0515]$} & 2.344 & .019 & 5566 \\
\hline Sex & -.0287 & .0297 & {$[-.0869, .0295]$} & -.967 & .334 & 5566 \\
\hline Age & -.0033 & .0019 & {$[-.0070, .0004]$} & -1.789 & .074 & 5566 \\
\hline Country (Germany) & .1578 & .0437 & {$[.0721, .2435]$} & 3.612 & $<.001$ & 5566 \\
\hline Country (the Netherlands) & -.2123 & .0443 & {$[-.2991,-.1255]$} & -4.790 & $<.001$ & 5566 \\
\hline \multicolumn{7}{|l|}{ Level 2: School Classes } \\
\hline Class Size & .0737 & .0170 & {$[.0404, .1070]$} & 4.338 & $<.001$ & 350 \\
\hline Diversity & -.0248 & .0193 & {$[-.0626, .0130]$} & -1.281 & .201 & 350 \\
\hline
\end{tabular}

Note. Level 1: $N=6,600$ students; Level 2: 353 school classes. TotAmCon denotes Total Amount of Contact t1. 
The unconditional model for future outgroup contact determined the variance proportion of the outcome variable across the two levels (individual students and school classes) with a resulting intraclass coefficient (ICC) of .0952. This ICC indicates that $9.52 \%$ of the variance in future outgroup contact is attributable to the class level, which differs significantly from zero, $\chi^{2}(350)=925.3778, p<.001$. The unconditional model for future ingroup contact revealed an ICC of .1067, which differs significantly from zero, $\chi^{2}(350)=1041.6098, p<.001$.

Model A revealed, in line with our hypothesis, a negative significant beta weight for the total amount of contact at time 1 on future outgroup contact $(B=-.0585, S E=.0107, p<.001$, $\left.C I_{95 \%}=-.0795,-.0375\right)$. This result indicates that the more (ingroup and outgroup) friends students have, the more saturated their contact capacity, and the less likely they are to make more outgroup friends. Similarly, future ingroup contact was negatively predicted by the total amount of contact the students already had in Model B $\left(B=-.1648, S E=.0215, p<.001, C I_{95 \%}=-.2069\right.$, -.1227). Furthermore, we modeled the cross-product term of group member status multiplied by total amount of contact at wave 1 (TotAmCon x Group Status) to establish if there are differences between majority and minority group members. Results show that group status (majority versus minority membership) is a significant moderator of the effect of total amount of contact at time 1 on both future outgroup $\left(B=-.0538, S E=.0260, p=.020, C I_{95 \%}=-.1048\right.$, $.0028)$ and future ingroup $\left(B=.0456, S E=.0261, p=.040, C I_{95 \%}=-.0056, .0968\right)$ contact; the negative effect of contact capacity on future outgroup contact is higher for minority members. It is worth noting that all findings regarding the core hypothesis can be replicated without control variables. $^{2}$

\section{Group-specific Future Outgroup Contact}


Table 4. Model A: Multilevel Prediction of Future Outgroup Contact in Majorities.

\begin{tabular}{|c|c|c|c|c|c|c|}
\hline & \multicolumn{6}{|c|}{ Model A: Majorities } \\
\hline & $B$ & $S E$ & $95 \% \mathrm{CI}$ & $t$ & $p$ & $D f$ \\
\hline \multicolumn{7}{|l|}{ Level 1: Students } \\
\hline Total Amount of Contact $\mathrm{t} 1$ & -.0325 & .0142 & {$[-.0603,-.0047]$} & -2.288 & .011 & 3261 \\
\hline Outgroup Contact t1 & .5301 & .0274 & {$[.4764, .5838]$} & 19.313 & $<.001$ & 3261 \\
\hline Outgroup Attitudes & .0076 & .0134 & {$[-.0187, .0339]$} & .566 & .571 & 3261 \\
\hline Sex & .0204 & .0323 & {$[-.0439, .0837]$} & 633 & .527 & 3261 \\
\hline Age & -.0002 & .0024 & {$[-.0049, .0045]$} & -.083 & .934 & 3261 \\
\hline \multicolumn{7}{|l|}{ Level 2: School Classes } \\
\hline Class Size & -.0091 & .0199 & {$[-.0481, .0299]$} & -.456 & .649 & 341 \\
\hline Diversity & .0664 & .0247 & {$[.0180, .1148]$} & 2.689 & .008 & 341 \\
\hline
\end{tabular}

Note. Level 1: $n_{\text {Majority }}=4,390$ students; Level 2: 353 school classes. 
Table 5. Model A: Multilevel Prediction of Future Outgroup Contact in Minorities.

\begin{tabular}{|c|c|c|c|c|c|c|}
\hline & \multicolumn{6}{|c|}{ Model A: Minorities } \\
\hline & $B$ & $S E$ & $95 \% \mathrm{CI}$ & $t$ & $p$ & $D f$ \\
\hline \multicolumn{7}{|l|}{ Level 1: Students } \\
\hline Total Amount of Contact t1 & -.0964 & .0208 & {$[-.1372,-.0556]$} & -4.624 & $<.001$ & 1662 \\
\hline Outgroup Contact t1 & .6419 & .0274 & {$[.5882, .6956]$} & 23.44 & $<.001$ & 1662 \\
\hline Outgroup Attitudes & .0087 & .0171 & {$[-.0248, .0422]$} & .509 & .611 & 1662 \\
\hline Sex & .0102 & .0311 & {$[-.0508, .0712]$} & .328 & .743 & 1662 \\
\hline Age & -.0035 & .0021 & {$[-.0076, .0006]$} & -1.678 & .094 & 1662 \\
\hline \multicolumn{7}{|l|}{ Level 2: School Classes } \\
\hline Class Size & .0320 & .0209 & {$[-.0090, .0730]$} & 1.530 & .127 & 333 \\
\hline Diversity & -.1025 & .0293 & {$[-.1599,-.0451]$} & -3.502 & $<.001$ & 333 \\
\hline
\end{tabular}

Note. Level 1: $n_{\text {Minority }}=2,210$ students; Level 2: 353 school classes. 
Following the significant group differences regarding the effect of total contact and future outgroup and ingroup contact, we continued to examine group-specific models. The unconditional model for majorities and their future contact with immigrant minorities revealed an ICC of .1191, which differs significantly from zero, $\chi^{2}(341)=845.0384, p<.001$. The unconditional model for minorities and their future outgroup contact with majority members revealed an ICC of .1443, which also differs significantly from zero, $\chi^{2}(333)=685.6904, p<$ .001.

Model A for majorities and minorities revealed, in line with our hypothesis, a negative significant beta weight for the total amount of contact at time 1 on future outgroup contact (majority: $B=-.0325, S E=.0142, p=.011, C I_{95 \%}=-.0603,-.0047$; minority: $B=-.0964, S E=$ $\left..0208, p<.001, C I_{95 \%}=-.1372,-.0556\right)$. Finally, our main finding can be replicated in four out of six country-specific submodels (majority sweden: $B=-.0503, S E=.0277, p=.034, C I_{95 \%}=-.1046$, .0040 ; minority Germany: $B=-.1346, S E=.0407, p<.001, C I_{95 \%}=-.2143,-.0548$; minority the Netherlands: $B=-.0796, S E=.0444, p=.037, C I_{95 \%}=-.1666, .0074$; minority sweden: $B=-.0826, S E$ $\left.=.0286, p=.002, C I_{95 \%}=-.1387,-.0265\right)$. See our supplementary online material for the submodels considered.

\section{Group-specific Future Ingroup Contact}

We established Model B, with a focus on predicting ingroup contact, to check whether we would find an effect of contact capacity on future ingroup contact in accordance with our theoretical background. In line with our hypothesis, results largely replicate the previous findings, as presented in Tables 6 and 7 (majority: $B=-.0893, S E=.0264, p<.001, C I_{95 \%}=$ 
Table 6. Model B: Multilevel Prediction of Future Ingroup Contact in Majorities.

\begin{tabular}{|c|c|c|c|c|c|c|}
\hline & \multicolumn{6}{|c|}{ Model B: Majorities } \\
\hline & $B$ & $S E$ & $95 \% \mathrm{CI}$ & $t$ & $p$ & $D f$ \\
\hline \multicolumn{7}{|l|}{ Level 1: Students } \\
\hline Total Amount of Contact t1 & -.0893 & .0264 & {$[-.1410,-.0376]$} & -3.390 & $<.001$ & 3832 \\
\hline Ingroup Contact t1 & .5067 & .0307 & {$[.4465, .5669]$} & 16.520 & $<.001$ & 3832 \\
\hline Ingroup Attitudes & .0324 & .0127 & {$[.0075, .0573]$} & 2.541 & .011 & 3832 \\
\hline Sex & -.0698 & .0342 & {$[-.1368,-.0028]$} & -2.044 & .041 & 3832 \\
\hline Age & -.0045 & .0023 & {$[-.0090, .0000]$} & -1.988 & .047 & 3832 \\
\hline \multicolumn{7}{|l|}{ Level 2: School Classes } \\
\hline Class Size & .0967 & .0224 & {$[.0528, .1406]$} & 4.325 & $<.001$ & 341 \\
\hline Diversity & -.0760 & .0270 & {$[-.1289,-.0231]$} & -2.812 & .005 & 341 \\
\hline
\end{tabular}

Note. Level 1: $n_{\text {Majority }}=4,390$ students; Level 2: 353 school classes. 
Table 7. Model B: Multilevel Prediction of Future Ingroup Contact in Minorities.

\begin{tabular}{|c|c|c|c|c|c|c|}
\hline & \multicolumn{6}{|c|}{ Model B: Minorities } \\
\hline & $B$ & $S E$ & $95 \% \mathrm{CI}$ & $t$ & $p$ & $D f$ \\
\hline \multicolumn{7}{|l|}{ Level 1: Students } \\
\hline Total Amount of Contact $\mathrm{t} 1$ & -.1182 & .0208 & {$[-.1590,-.0774]$} & -5.683 & $<.001$ & 1414 \\
\hline Ingroup Contact t1 & .6332 & .0336 & {$[.5673, .6991]$} & 18.842 & $<.001$ & 1414 \\
\hline Ingroup Attitudes & -.0001 & .0191 & {$[-.0375, .0373]$} & -.006 & .995 & 1414 \\
\hline Sex & .0523 & .0598 & {$[-.0649, .1695]$} & .874 & 382 & 1414 \\
\hline Age & -.0017 & .0028 & {$[-.0072, .0038]$} & -.590 & .555 & 1414 \\
\hline \multicolumn{7}{|l|}{ Level 2: School Classes } \\
\hline Class Size & .0663 & .0247 & {$[.0179, .1147]$} & 2.684 & .008 & 325 \\
\hline Diversity & .0657 & .0236 & {$[.0194, .1120]$} & 2.779 & .006 & 325 \\
\hline
\end{tabular}

Note. Level 1: $n_{\text {Minority }}=$ 2,210 students; Level 2: 353 school classes. 
-.1410, -.0376; minority: $\left.B=-.1182, S E=.0208, p<.001, C I_{95 \%}=-.1590,-.0774\right)$. The findings can also be replicated in five out of six country-specific submodels (majority Germany: $B=-.1219$, $S E=.0457, p=.004, C I_{95 \%}=-.2115,-.0323$; majority Sweden: $B=-.1168, S E=.0382, p<.001$, $C I_{95 \%}=-.1917,-.0419$; minority Germany: $B=-.1127, S E=.0311, p<.001, C I_{95 \%}=-.1737,-.0517$; minority the Netherlands: $B=-.0949, \mathrm{SE}=.0382, \mathrm{p}=.007, \mathrm{CI}_{95 \%}=-.1698,-.0200$; minority Sweden: $\mathrm{B}$ $\left.=-.1504, \mathrm{SE}=.0352, \mathrm{p}<.001, \mathrm{CI}_{95 \%}=-.2194,-.0814\right)$. See our supplementary online material for the submodels considered.

\section{Discussion}

The present study aimed to ascertain whether contact capacity affects intergroup contact. Given the limited cognitive and social resources individuals have for social relations, the role of contact capacity was introduced and empirically examined to test if this variable helps to explain the likelihood of engaging in future outgroup contact. Results showed that contact capacity (measured as the total amount of social network ties with both ingroup and outgroup members) is negatively associated with the individuals’ interest in establishing future out- and / or ingroup contact. These effects remained stable in both main models that predicted future outgroup and future ingroup contact, across both the majority and minority, as well as in nine out of the 12 country-specific models. . It is worthy to note that all results are based on social network data, which provide some important advantages for the field of intergroup relations and this research question in particular. We now first discuss these results in terms of the importance of contact capacity for intergroup contact experiences, before acknowledging limitations and identifying avenues for future research. 
The unique structure of the CILS4EU panel (e.g., participant recruitment, selection procedures, large sample, international data) allowed us to investigate social network effects in three European countries over time while taking both majority and minority perspectives into account. By using a large-scale dataset, the study supported the theoretical account in terms of contact capacity across groups (majority and minority), outcomes (outgroup contact and ingroup contact), and contexts (Germany, the Netherlands, and Sweden). Two major points arise from this analysis. First, these results indicate the high external validity of the study as the relationship between contact capacity and future intergroup contact can be largely generalized to different measures and populations longitudinally. Second, the effect of contact capacity is robust while controlling for intergroup attitudes. This is of special importance for the given study, because it highlights that, independent of how positive intergroup attitudes are, or indeed how positive intergroup contact is (whether it is measured or manipulated), intergroup interactions may not reach their potential if the contact capacity of an individual is already saturated. Our study extends previous literature by addressing a gap in intergroup contact research: the present study considers the impact of contact capacity as a factor that influences the formation of future inand, of particular relevance for intergroup contact, outgroup contact in a negative way. Thus, it provides us with a better understanding of why some people take up existing intergroup contact possibilities and others do not: not only limited time to engage in new contact, but also limited cognitive resources can serve as an explanation why intergroup contact opportunities can sometimes translate into meaningful contact and sometimes not. A saturated social network can prevent individuals from engaging in further contact situations with members of both outgroup (and ingroup) as these situations can be associated with cognitive load (Saramäki et al., 2014). Even though we were not able to show an effect of contact capacity in three out of 12 country- 
specific submodels, the effect in each of these three cases goes in the predicted direction, with non-significant negative associations between contact capacity and future outgroup (and ingroup) contact.

Comparing the results for future outgroup (and ingroup) contact between the majority and minority, we find that the negative effect of contact capacity on future outgroup (and ingroup) contact is higher for minority members. This interesting finding deserves further research to determine the reasons for the decline, considering that it can impact minorities' integration into the host country and the establishment of a functioning social structure at the same time.

\section{Limitations and Future Research Directions}

We acknowledge five limitations which might signal future research directions. First, the study falls short of explicitly considering minority group-specific contact. Given the structure of the CILS dataset and the relatively small networks (restricted to school classes), it is not possible to take into account immigrant minority children who are friends with another immigrant minority group member. Future research should therefore be conducted in larger social networks with more opportunities for minority members to get in touch with different immigrant subgroups to investigate more precisely factors influencing intergroup contact in minority subgroups.

Second, future research could explore the effect of contact capacity beyond friendship, which we examined in this paper, on other forms of contact, including both general and negative intergroup contact, as the outcome might depend on the form of contact. Research focusing on negative contact, for example, states that negative contact experiences make group membership more salient (Paolini, Harwood, \& Rubin, 2010). Transferred to the given context, minority members might perceive a higher risk of rejection when engaging in intergroup contact as they 
hold only mildly favourable attitudes towards themselves as a group. Thus, they may repeat behaviours that have been successful in the past rather than risking future negative outgroup contact experiences (i.e. rejection by the majority). We already see this stronger negative tendency in minorities with regard to future outgroup contact and thus assume that this effect will further increase under negative contact conditions.

Third, future research could also consider the role of direct versus extended contact experiences with regard to contact capacity. Direct contact is defined as the person him- or herself having an outgroup friend (as measured by our social network ties with outgroup members), whereas extended contact is the phenomenon whereby knowing that a member of one’s group has a close friend from another group can improve one’s attitudes toward that group (Wright, Aron, McLaughlin-Volpe, \& Ropp, 1997). While a saturated social network can prevent individuals from engaging in direct contact with additional members of outgroups (and ingroups) - as these situations can be associated with cognitive load - extended contact presents an alternative for people with compromised contact capacity. That is, for individuals with a saturated network, extended contact would represent an alternative opportunity to (indirectly) engage in outgroup contact. Given that extended contact has reliably been found to improve intergroup relations beyond direct contact (for meta-analytic evidence, see Zhou et al., 2018), even individuals with high levels of pre-existing direct contact can still benefit indirectly from knowing about others’ intergroup interactions. Perhaps an optimal intervention would identify and explicitly consider individuals’ overall network and their total amount of contact before conducting the intervention, so that researchers could then tailor intervention strategies to the specific needs of individuals. 
Fourth, despite the potential of SNA, the method brings with it some limitations, such as the restricted social network measure of the five most important friends in the given study. It is crucial to limit the nominations to prevent participants from an inflationary use of the friendship definition as some of the students might be inclined to nominate all peers in the classroom. However, future research should consider other forms of contact and address whether the social network of people is saturated beyond a specific setting, such as school classes in our analysis, and consider the entire ego network of each individual.

Fifth, the need to belong could be considered as a moderator explaining the relationship between contact capacity and future intergroup contact. We assume that individuals who have a small total amount of contact will engage in more future outgroup contact when they have a high, compared to a low, level of the need to belong.

In conclusion, the present study emphasizes the importance of contact capacity for contact research as it helps to explain the mechanisms that can sometimes prevent intergroup contact from having a profound impact on intergroup attitudes and thus reducing prejudice effectively. Though we demonstrate the negative effect of contact capacity on intergroup relations, further longitudinal assessments of the impact of contact capacity are needed to improve our understanding of intergroup contact and cross-group friendships between majority and minority members. In particular, this will allow intergroup contact research to contribute significantly to the development of research-based interventions for improving intergroup relations to guarantee a peaceful coexistence of people from different cultures and ethnicities. 


\section{References}

Allport, G. W. (1954). The nature of prejudice. Reading, MA: Addison-Wesley.

Baumeister, R. F., \& Leary, M. R. (1995). The need to belong: Desire for interpersonal attachments as a fundamental human motivation. Psychological Bulletin, 117(3), 497-529. doi:10.1037/0033-2909.117.3.497

Champely, S., Ekstrom, C., Dalgaard, P., Gill, J., Weibelzahl, S., Ford, C., . . . De Rosario, M. H. (2017). Package 'pwr'. Retrieved from https://cran.rproject.org/web/packages/pwr/pwr.pdf

CILS4EU. (2016). Children of Immigrants Longitudinal Survey in Four European Countries [Codebook Wave 1 - 2010/2011, v1.2.0.]. Mannheim: Mannheim University. Retrieved from http://www.cils4.eu/images/wave1_material/codebook/za5353_cod_wave1.pdf

CILS4EU. (2016). Children of Immigrants Longitudinal Survey in Four European Countries [Technical Report Wave 1 - 2010/2011, v1.2.0.]. Mannheim: Mannheim University. Retrieved from http://www.cils4.eu/images/wave1_material/technical/za5353_technicalreport_wave1.pdf

Clifton, A. D., \& Webster, G. D. (2017). An introduction to social network analysis for personality and social psychologists. Social Psychological and Personality Science, 8, 442453. doi:10.1177/1948550617709114

Cohen, J. (1988). Statistical power analysis for the behavioral sciences (2nd ed.). Hillsdale, NJ: Erlbaum.

Davies, K., Tropp, L. R., Aron, A., Pettigrew, T. F., \& Wright, S. C. (2011). Cross-group friendships and intergroup attitudes: A meta-analytic review. Personality and Social Psychology Review, 15(4), 332-351. doi:10.1177/1088868311411103 
Dunbar, R. I. M. (1993). Coevolution of neocortical size, group size and language in humans. Behavioral and Brain Sciences, 16(4), 681-735. doi:10.1017/S0140525X00032325

Kalter, F., Heath, A. F., Hewstone, M., Jonsson, J. O., Kalmijn, M., Kogan, I., \& van Tubergen, F. (2016a). Children of Immigrants Longitudinal Survey in Four European Countries (CILS4EU) - Full version. Data file for on-site use. GESIS Data Archive, Cologne, ZA5353 Data file Version 1.2.0.

Kalter, F., Heath, A. F., Hewstone, M., Jonsson, J. O., Kalmijn, M., Kogan, I., \& van Tubergen, F. (2016b). Children of Immigrants Longitudinal Survey in Four European Countries (CILS4EU) - Full version. Data file for on-site use. GESIS Data Archive, Cologne, ZA5353 Data file Version 2.3.0.

Kobe, F. H., \& Mulick, J. A. (1995). Attitudes toward mental retardation and eugenics: The role of formal education and experience. Journal of Developmental and Physical Disabilities, 7(1), 1-9. doi:10.1007/BF02578710

Laurence, J., Schmid, K., Rae, J. R., \& Hewstone, M. (in press). Prejudice, contact and threat at the diversity-segregation nexus: A cross-sectional and longitudinal analysis of how ethnic out-group size and segregation interrelate for inter-group relations. Social Forces.

McPherson, M., Smith-Lovin, L., \& Cook, J. M. (2001). Birds of a feather: Homophily in social networks. Annual Review Of Sociology, 27415-444. doi:10.1146/annurev.soc.27.1.415

Munniksma, A., Stark, T. H., Verkuyten, M., Flache, A., \& Veenstra, R. (2013). Extended intergroup friendships within social settings: The moderating role of initial outgroup attitudes. Group Processes \& Intergroup Relations, 16(6), 752-770.

doi:10.1177/1368430213486207 
Paolini, S., Harwood, J., \& Rubin, M. (2010). Negative intergroup contact makes group memberships salient: Explaining why intergroup conflict endures. Personality and Social Psychology Bulletin, 36(12), 1723-1738. doi:10.1177/0146167210388667

Pettigrew, T. F. (1998). Intergroup contact theory. Annual Review of Psychology, 4965-85. doi:10.1146/annurev.psych.49.1.65

Pettigrew, T. F., \& Tropp, L. R. (2006). A meta-analytic test of intergroup contact theory. Journal of Personality and Social Psychology, 90(5), 751-783. doi:10.1037/00223514.90.5.751

Raudenbush, S. W., \& Bryk, A. S. (2002). Hierarchical linear models: Applications and data analysis methods (2nd ed.). Thousand Oaks, CA: Sage.

Saramäki, J., Leicht, E. A., López, E., Roberts, S. G. B., Reed-Tsochas, F., \& Dunbar, R. I. M. (2014). Persistence of social signatures in human communication. Proceedings of the National Academy, 111(3), 942-947. doi:10.1073/pnas.1308540110

Shelton, J. N., Trail, T. E., West, T. V., \& Bergsieker, H. B. (2010). From strangers to friends: The interpersonal process model of intimacy in developing interracial friendships. Journal of Social and Personal Relationships, 27(1), 71-90. doi:10.1177/0265407509346422

Turner, R. N., Hewstone, M., \& Voci, A. (2007). Reducing explicit and implicit outgroup prejudice via direct and extended contact: The mediating role of self-disclosure and intergroup anxiety. Journal of Personality and Social Psychology, 93(3), 369-388. doi:10.1037/0022-3514.93.3.369

van der Meer, T., \& Tolsma, J. (2014). Ethnic diversity and its effects on social cohesion. Annual Review Of Sociology, 40459-478. doi:10.1146/annurev-soc-071913-043309 
Vezzali, L., Hewstone, M., Capozza, D., Trifiletti, E., \& Di Bernardo, G. A. (2017). Improving intergroup relations with extended contact among young children: Mediation by intergroup empathy and moderation by direct intergroup contact. Journal of Community \& Applied Social Psychology, 27(1), 35-49. doi:10.1002/casp.2292

Ward, C., \& Rana-Deuba, A. (2000). Home and host culture influences on sojourner adjustment. International Journal of Intercultural Relations, 24(3), 291-306. doi:10.1016/S01471767(00)00002-X

Wölfer, R., \& Hewstone, M. (2017). Beyond the dyadic perspective: 10 reasons for using social network analysis in intergroup contact research. British Journal of Social Psychology, 56(3), 609-617. doi:10.1111/bjso.12195

Wölfer, R., \& Hewstone, M. (2018). What buffers ethnic homophily? Explaining the development of outgroup contact in adolescence. Developmental Psychology. (early online version)

Wölfer, R., \& Scheithauer, H. (2013). Ostracism in childhood and adolescence: Emotional, cognitive, and behavioral effects of social exclusion. Social Influence, 8(4), 217-236. doi:10.1080/15534510.2012.706233

Wölfer, R., Schmid, K., Hewstone, M., \& van Zalk, M. (2016). Developmental dynamics of intergroup contact and intergroup attitudes: Long-term effects in adolescence and early adulthood. Child Development, 87(5), 1466-1478. doi:10.1111/cdev.12598

Wright, S., Aron, A. \& McLaughlin-Volpe, T., Ropp, S. A. (1997). The extended contact effect: Knowledge of cross-group friendships and prejudice. Journal of Personality and Social Psychology, 73, 73-90. 10.1037/0022-3514.73.1.73. 
Zhou, S., Page-Gould, E., Aron, A., Moyer, A., \& Hewstone, M. (2018). The extended contact hypothesis: A meta-analysis on 20 years of research. Personality and Social Psychology Review.

Zhou, W.-X., Sornette, D., Hill, R. A., \& Dunbar, R. I. M. (2005). Discrete hierarchical organization of social group sizes. Proceedings of the Royal Society B: Biological Sciences, 272(1561), 439-444. doi:10.1098/rspb.2004.2970st 


\section{Footnotes}

${ }^{1}$ See CILS4EU (2016) Technical Report Wave 1 - 2010/2011, v1.2.0. for a complete and detailed documentation of the data and measures collected in the CILS4EU study. See CILS4EU (2016) Codebook Wave 1 - 2010/2011, v1.2.0. for a complete and detailed documentation of the data and measures collected in the CILS4EU study.

${ }^{2}$ The core model that includes only the effects relevant for our hypothesis (as well as the necessary autoregressive effect of initial total contact at wave 1) supports all other models regarding the effects of future outgroup $\left(B=-.0801, S E=.0102, p<.001, C I_{95 \%}=-.1001\right.$, $.0601)$ and future ingroup $\left(B=-.1628, S E=.0144 p<.001, C I_{95 \%}=-.1910,-.1346\right)$ contact. 